\title{
Cultural Differences in the Study of Public Administration*
}

\author{
Mei-hua Cheng** and Chyung-en Wu***
}

\begin{abstract}
There are two kinds of truth: extensional (objective) and intentional (subjective). Western culture has traditionally foregrounded extensional truth, while Chinese culture has focused on intentional truth. This paper focuses on intentional truth, which has not been given sufficient attention in the study of public administration. Action knowledge is more valuable than a science of administration, and we need to develop it. All learning takes place inside individuals, so all organizational learning is individual learning. Meanwhile, tacit knowledge must be made explicitly before it can be gainfully deployed. An organization's competitiveness depends on its tacit knowledge, not its explicit knowledge, and the same is true of public administration. This paper uses hermeneutical methods to analyze the meaning of administrative action in organizations from different cultural viewpoints. To deal with the global economic crisis, it is important to develop action knowledge to support theories of how financial crises develop and how they could be avoided, so as to reform the institutionalized paradigm of public administration and governance and to cooperate in dealing with the economic crisis.
\end{abstract}

Keywords: knowledge creation, extensional truth, nonquantitative human factors, sympathized knowledge

* This is a revised version of a paper given at the international conference Public Administration and Governance in a Time of Global Economic Turbulence: Searching for New Paradigms, organized by the Korea Institute of Public Administration (KIPA), in Seoul on October 9, 2009. The authors would like to express their deep gratitude to three anonymous reviewers for their perspectives and valuable comments.

** Mei-hua Cheng, an assistant professor in the School of Liberal Education at Shih-Chien University in Taiwan, earned her $\mathrm{PhD}$ from the National Chen-chi university. She was formerly director of the Third Department of Council for Cultural Affairs, Executive Yuan, Taiwan. Her research interests include political philosophy, public administration, creative industry, and crisis management. Email: jmhcheng@mail.usc.edu.tw.

*** Chyung-en $\mathrm{Wu}$, a Professor in the Public Administration Department at Chen-chi University in Taiwan, earned his $\mathrm{PhD}$ from the University of Texas at Austin. He was formerly head of the Public Administration Department and Institute at Chen-chi University. His research interests include political philosophy, public administration, knowledge management, and human resource management. Email: wqe@faculty.pccu.edu.tw.

Manuscript received February 8, 2010; out for review March 8, 2010; review completed April 16, 2010; accepted April 19, 2010.

The Korean Journal of Policy Studies, Vol. 25, No. 1, 193-210 (2010)

(C) 2010 by the GSPA, Seoul National University 


\section{INTRODUCTION}

The American financial crisis occured in the end of 2008 worsened into a global financial turbulence that has affected Asia, North and South America, Europe, and the rest of the world. These are difficult years for the world economy, and no country has developed the effective policy to resist the economic turbulance.

Financial crises related to banking panics have often been followed by recession or depression. Some kinds of financial crises directly cause a loss of paper wealth, and some include financial bubbles, stock market crashes, and currency crises, and directly or indirectly influence economic development (Laeven and Valencia 2008; Kindleberger and Aliber 2005).

Base on the President of Asian Development Bank, Haruhiko Kuroda (2009), financial markets and currencies continue to stabilize throughout the region. The relatively rapid and orderly process of financial adjustment was due to flexible exchange rate regimes and the lack of domestic financial excess. ${ }^{1}$

And according to the chief of the International Monetary Fund, Dominique Strauss-Kahn (2009), the growth model after the economic crisis has been destroyed. It is not only lost purchasing power or unemployment, but life and death, starvation and refugees. Some of the reduced consumption in the U.S. can be compensated by higher consumption in some rising countries, and increased consumption in China will not create the same kind of demand as in the U.S. ${ }^{2}$

Every country's economists have offered theories about how financial crises develop and how they could be prevented. Since this economic crisis is hardly explainable and predictable by existing social science theories, we must renew our efforts to review our experiences, theorize them, and find solutions.

Our research probes cultural differences in the study of public administration in order to explore different perspectives in the eastern and western worlds, reconsider existing approaches, and reform the institutionalized paradigm of public administration and governance.

1. Haruhiko Kuroda, President of Asian Development Bank. "Asia's recovery from the global financial crisis: What it takes and what could ADB do?" Lecture on 22 June 2009. http://www.adb.org/Documents/Speeches/2009/ms2009049.asp.

2. Emerson, T. and Sheridan B. 2009. Dominique Strauss-Kahn: The constant crisis, Newsweek, Sep 26, 2009. http://www.newsweek.com/id/216214. 


\section{HOLISTIC AND ECOLOGICAL VIEWS VS. MECHANISTIC AND REDUCTIONIST APPROACHES}

In the twenty-first century, there are two parallel currents in the study of public administration: the search for international principles, and the drive to localization. These currents raise the question of whether western public administration theory can be applied universally, and more importantly, whether local conceptions of public administration can be applied to the West. Public administration is acutely concerned with the relationship between knowledge and action, and particularly with the issue of individual differences vs. cultural differences. We must therefore carefully consider the epistemologies of eastern and western cultures, and how they are mixing in the era of globalization.

In the introduction to Order out of Chaos (Prigogine and Stengers 1984), Nobel Prize winner Ilya Prigogine claimed that a new dialogue has started between man and nature. Prigogine said that man is in the process of creating a "new nature," and quoted the Chinese philosopher Zhuangzi:

How [ceaselessly] Heaven revolves! How [constantly] Earth abides at rest! Do the Sun and the Moon contend about their respective places? Is there someone presiding over and directing those things? Who binds and connects them together? Who causes and maintains them without mechanism in consequence of which they cannot be as they are? ( Prigogine and Stengers 1984, 22)

Prigogine and Stengers were hopeful about the mixing of Chinese and western culture, saying (1984): "We believe that we are heading toward a new synthesis, a new naturalism. Perhaps we will eventually be able to combine the western tradition, with its emphasis upon experimentation and quantitative formulations, with a tradition such as the Chinese one, with its view of a spontaneous, self-organizing world" (Prigogine and Stengers 1984, 22).

In the twentieth century, physics underwent a paradigm shift that radically altered its Newtonian empiricist model. Werner Heisenberg, one of the developers of quantum physics, explained the crisis of empiricism as follows:

Every word or concept, however, clear as it may seem to be, has only a limited range of applicability. Scientific theories will always be the approximation to the true nature of things. To put it bluntly, scientists do not deal with truth; they deal with limited and approximate descriptions of reality.

To transcend the classical models scientists will have to go beyond the mechanistic and reductionist approach as we have done in physics, and develop holistic and ecological views (Capra 1982, 48-49; Heisenberg 1975, 389-394; 1999). 
Today, the effects of the financial crisis are still reverberating throughout the world, interest rates have risen, businesses are closing, bad debts are mounting, jobs are being lost, prices are rising, exports are down, stock markets are sagging, exchange rates are fluctuating, and foreign capital is draining away. The impact of the financial crisis can be seen in the increasing instability of political and social institutions, and in the various responses of states around the world. In responses to the financial crisis, we can find connections between governance models and cultural differences.

\section{PURPOSE OF RESEARCH}

This research has three purposes: (1) It aims to differentiate positivism from naturalism and the methodological point of view, based on examples from the world of physical science. (2) It explores similarities between the worldview of eastern philosophy and that of naturalism, especially in its emphasis on the oneness of nature and human, value and fact, and knowing and action, in which the Tao (that is, tacit knowledge) is beyond the limit of empiricism. (3) It argues that in the decision-making process, intuitive capacity is more important than rational choice, which means that cultural differences affect the decision-making process and that it is difficult to make generalizations about it.

\section{METHOD OF RESEARCH}

Using hermeneutical methods to interpret the meaning of administrative behavior in organizations from the viewpoint of cultural difference, the authors agree with Lincoln and Guba's (1985) argument that (1) believing is seeing, (2) action precedes intention, and (3) goals are discovered by acting. These three points are similar to tenets found in traditional Chinese philosophy, especially Confucianism, Taoism, and Buddhism.

The dominant paradigm in contemporary physics is very similar to Chinese traditional thought. To put it another way: the more traditional a worldview is, the more modern it is (Capra 1982, 1985; Wu 2005, 2006). The social sciences, particularly public administration, should draw inspiration from this situation.

The methodology of the research is based on the analysis of Schwartz and Ogilvy (1979:13), which describes seven aspects of a shift from positivism to naturalism:

1. from a simple and probabilistic world view toward a view of reality that is 
complex and diverse

2. from a hierarchically ordered world to a world ordered by heterarchy

3. from the image of a mechanistic and machine-like universe toward one that is holographic

4. from the image of a determinate universe to that of an indeterminate one

5. from the assumption of direct causality to the assumption of mutual causality

6. from the metaphor of assembly to the metaphor of morphogenesis

7. from a posture of pure objectivity-the posture that has been thought to characterize the scientist or researcher-to a posture that is perspectival (Lincoln and Guba 1985, 34-36)

From the above statement, it appears that the naturalistic viewpoint is similar to the traditional eastern worldview or paradigm. According to Lincoln and Guba (1985, 102), naturalistic inquiries tend to be carried out in natural settings, as opposed to contrived, laboratory, or experimental settings.

According to the methodology of logical positivism, science is just a search for truth. The authors agree with Karl Popper's viewpoints (1968, 1969, 1979), that there is no way to find truth because of the limitations of human rationality, and that therefore, science can only be the search for verisimilitude. This paper argues against logical positivism not only because it has been decreasing in acceptance since the 1960s, but its assumptions are like Newton's theory of physics that hold for all situations, yet not against to the positive method besides positivism as we do not oppose the scientific method besides scientism.

Chinese epistemological traditions stress unity - of nature and man, mind and body, mind and matter, self and other, and so forth. Western traditions take the opposite approach. ${ }^{3}$ With this in mind, we can locate the epistemological assumptions behind the theories of the economical scientist Herbert A. Simon (1991):

1. The individual is more important than the group.

2. Explicit knowledge is more important than tacit knowledge.

Reflecting the first assumption, Simon $(1991,125)$ said, "All learning takes place inside individual human heads." All organizational learning is, by definition, individual learning. The second assumption led Simon to argue that while tacit knowledge is at the heart of knowledge creation, it must be made explicit before it can be gainfully deployed. He failed to see that an organization's competitiveness lies in its tacit knowledge, not its explicit knowledge.

3. Nonaka and Takeuchi (1995), chapter 2 for a full analysis. Hsiung Shih-li (1997, 1999, 2000), Tang Jun-yi (1991), and Mou Zong-san (1960, 2003). 


\section{DISCUSSION}

\section{Tacit Knowledge is a Simple Fact of Life}

The Hungarian-British philosopher Michael Polanyi (1958), writing in Personal Knowledge about tacit and explicit knowledge, said that explicit knowledge can be formally expressed and directly communicated, whereas tacit knowledge can be experienced but is difficult to express verbally. Explicit knowledge can be obtained by taking classes, copying, and learning; tacit knowledge is obtained through practice and experience. Tacit knowledge requires special methods to transmit, learn, accumulate, and put into practice. Polanyi $(1967,4)$ argued that the fact that "we can know more than we can tell" is a simple fact of life, backed up by science, and this demonstrates the existence of tacit knowledge.

Japanese corporate culture provides an example of a culture that reverses Simon's two assumptions: in Japan, the group is more important than the individual, and tacit knowledge is more important than explicit knowledge. These Japanese assumptions match Chinese traditional thought.

In The Knowledge-Creating Company (1995), Nonaka and Takeuchi examined how Japanese organizations create knowledge, using Asian epistemological categories. The model they produced was based on Asian thinking and Asian companies, yet it is general enough in scope that it can be applied to western organizations. This is a perfect example of a theory that is both localized and international in scope.

Nonaka and Takeuchi first described the major features of tacit and explicit knowledge, saying that tacit knowledge is subjective while explicit knowledge is objective. Table 1 compares the key features that they distinguished.

Table 1. Tacit and Explicit Know ledge

\begin{tabular}{ll}
\hline \multicolumn{1}{c}{ Tacit knowledge (subjective) } & \multicolumn{1}{c}{ Explicit knowledge (objective) } \\
\hline Knowledge of experience (body) & Knowledge of rationality (mind) \\
Simultaneous knowledge (here and now) & Sequential knowledge (there and then) \\
Analog knowledge (practice) & Digital knowledge (theory) \\
\hline
\end{tabular}

Source: Nonaka and Takeuchi 1995, 61.

Transfers between these two types of knowledge can produce four different modes of learning, which in turn produce different kinds of knowledge, as described in figure 1. 
Figure 1. Knowledge Created by the Four M odes of Learning

\begin{tabular}{|c|c|c|}
\hline & Tacit knowledge & Explicit knowledge \\
\hline Tacit knowledge & $\begin{array}{c}\text { (Socialization) } \\
\text { Sympathized knowledge }\end{array}$ & $\begin{array}{c}\text { (Externalization) } \\
\text { Conceptual knowledge }\end{array}$ \\
\hline Explicit knowledge & $\begin{array}{c}\text { (Internalization) } \\
\text { Operational knowledge }\end{array}$ & $\begin{array}{c}\text { (Combination) } \\
\text { Systemic knowledge }\end{array}$ \\
\hline
\end{tabular}

Source: Nonaka and Takeuchi 1995, 72.

The process of socialization produces sympathized knowledge. This is a long-term process of immersion and absorption, as tacit knowledge is transferred from one individual to another. It can be compared to the Zen concept of transmitting knowledge directly from mind to mind. The second type of knowledge emerges in the gradual process of externalizing tacit knowledge. Tacit knowledge is externalized as concepts (conceptualized), which can be thought, operated on, and expressed in language. Third is the internalization of explicit knowledge, in which concepts are translated into operational practice, producing skilled behavior, know-how, or knacks. Finally, explicit knowledge can be combined with other explicit knowledge to produce broader, more systemic knowledge. An example would be combining economics with organization theory to produce the new discipline of organizational economics.

\section{Extensional Truth vs. Intentional Truth}

Mou Zong-san (2003, 19-43) defined two kinds of truth: extensional and intentional. Extensional truths are basically scientific truths, concerning objective features of real objects. Intentional truths are subjective attitudes associated with the self. They are not scientific truths; they cannot be extensionalized. But they are a form of truth.

Extensional truths are broad and universal; intentional truths are deep. They can be understood and shared through writing. They have their own reality, which is intentional universality. These are issues of religion and morality, aspects of which have long been ignored in public administration and the social sciences.

Mou (2003), extensional truths have abstract universality, while intentional truths have concrete universality. Hegel termed Concrete universality is a concept used in concrete philosophy, such as morality, religion, aesthetics, and history (Mou 2003, 32). Mou stated: "Confucius did not describe ren in abstract terms. Ren can be realized 
concretely in real life, so Confucius always directed us to concrete incidents in real life as manifestations of ren." (Mou 2003, 35) The universality of intentional truths is revealed in concrete events.

Ernst Cassire (1944, 32-68), a philosopher of contemporary culture, saying that tacit knowledge is a kind of intentional truth, the knowledge that is manifested in the concrete course of life, or in the process of administration. According to Cassirer, this kind of truth is also universal.

Lee Sheng-lung (2004), thinking of this kind of tacit knowledge, the Confucian thinker Wang Yang-ming proposed that "knowledge and action form a unity."4 Cognition and action are interrelated. The same concept exists in contemporary knowledge management. Cook and Brown (1999) distinguished the epistemology of possession from the epistemology of knowing. Possession is the static possession of knowledge. Knowing is a dynamic form of cognition. The two are complementary, and develop in concert.

Over the past century or more, the epistemological structures employed in public administration have basically been those of positivism and logical empiricism. In examining behavior within organizations, they concentrate on extensional propositions, that is, those with cognitive significance. However, human life is an integral whole, involving both scientific universals and its own sense of reality. An individual's sense of reality is knowledge in the form of intentional propositions.

This form of knowledge has in the past been neglected in studies of public administration. Few authors have constructed problems or theories based on the subjective experience of those who are subject to the administrative system, their sense of powerlessness, normlessness or self-estrangement. The result is that public administration theories have been one-dimensional.

If knowledge were divided into explicit knowledge and tacit knowledge, located in the individual or group, then knowledge as action can be placed at the center as in figure 2 .

Four forms of knowledge are represented in figure 2. The first is explicit knowledge formed by individuals through cognition and action, such as abstract concepts, principles, and theories. The second is explicit knowledge at the group level: expressing experiences or work processes through stories, including shared metaphors and phrases. The third is individual tacit knowledge, such as skills in making use of concepts, schemata, and mental models, and beliefs that are assumed to be true. The fourth is group tacit knowledge, such as eastern nationalism or organizational climate,

4. Lee, S. 2004. 王陽明傳習錄 [An Essay on collective learning of Wang young ming]. Taipei: San Min. 
Figure 2. Knowledge and Cognition

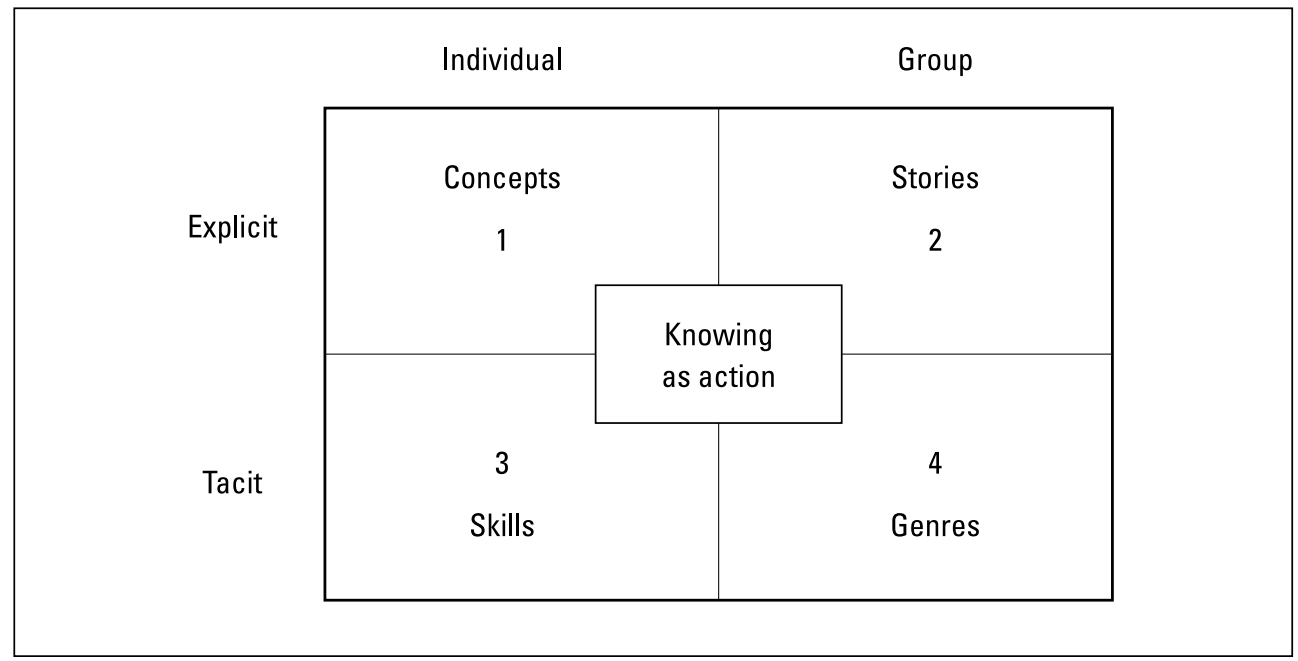

Source: Cook and Brown 1999, 383.

and so forth.

All of the semantic categories are formed tacitly at the group level. For example, two organizations may hold meetings that each refers to as "gatherings," but in one organization these may be decision-making events and in the other just informal gettogethers. Members of an organization are influenced by its culture, and naturally assign group-specific meanings and categories to certain objects and actions.

Eastern culture prizes tacit knowledge at both the individual and group levels. Confucius described the superior man in this way: "He puts his words into action before allowing his words to follow his action." (Wu 2006:201, 689-691). Zhuangzi said, "Those who know do not speak; those who speak do not know. Therefore the sage practices the teaching that has no words." (Wu 2006:201, 689-691). Laozi said, "Much speech leads inevitably to silence." (Wu 2006:201, 689-691). ${ }^{5}$ These quotes are basically equivalent to what Polanyi (1966) said in The Tacit Dimension "We can know more than what we can tell." In addition to personal tacit knowledge, there is group tacit knowledge-for example, the nationalism of the Chinese and other eastern groups, which westerners find so hard to understand. The former U.S. Secretary of Defense Robert MacNamara (1995), recorded in his memoirs that in his analysis, the

5. See the classic works of Chinese Confucianism, Buddhism, and Taoism, and the works of Hsiung Shih-li (1997, 1999, 2000), and Wu (2006) contains a more detailed account of communication theory. 
failure of the Vietnam War was a failure to comprehend Asian nationalism. ${ }^{6}$

Action science is different from behavioral science. It is a management strategy to increase people's abilities, skills, and confidence in groups, so as to build an organization and cultivate individual and group effectiveness in the long term. While people work on challenging tasks corporately, action science can be applied to interpersonal relations, organizations, and other group contexts (Agyris, et al. 1985).

The methodology of western public administration studies has tended towards logical positivism, and its theories are logical and linguistic, displaying a mechanistic rationality. F.W. Taylor's Scientific Management (1911), Herbert. A. Simon's Administrative Behavior (1945, 1991), M. Porter's Competitive Strategy (1980)—-these works all foreground logic and analytical, extensional knowledge. They neglect another, more eastern approach to cognition, which emphasizes its active and nonlinguistic aspects. Western tradition prizes scientific knowledge, while eastern traditions favor action knowledge. Action knowledge is not behavioral science, strictly speaking; it should be action knowledge, rather than behavior knowledge (Agyris, et al. 1985).

Early in the history of public administration studies, Chester Barnard described action knowledge this way:

The essential aspect of the executive process is the sensing of the organization as a whole and the total situation relevant to it. It transcends the capacity of merely intellectual methods, and the techniques of discriminating the factors of the situation. The terms pertinent to it are "feeling," "judgment," "sense," "proportion," "balance," "appropriateness." It is a matter of art rather than science, and is aesthetic rather than logical. For this reason it is recognized rather than described and is known by its effects rather than by analysis (Barnard 1938, 235).

Barnard believed that action knowledge was a nonlogical mental process, and that it was much more important than scientific knowledge, which was associated with logical mental processes.

Thus it can be seen in Barnard's concept of behavioral knowledge in 1938. It is totally different from the behavioral knowledge of behavioral science during 1950s to 1960s. In other words, it would be better to call the formal behavioral knowledge as action knowledge. Apparently, the behavioral science tends to search for the generalization of external behavior without interpreting the meaning of external behavior from the viewpoints of behavior's motivation and context like action science in 1980s (Argyris et al. 1985; M. Harmon 1981).

Since then, public administration studies have developed two major strands. The

6. MacNamara, R., et al. 1995. In retrospect: The tragedy and lessons of Vietnam. 
scientific approach includes Frederick W. Taylor's scientific management (1911); Herbert A. Simon's information-processing paradigm (1991); and Michael Porter's science of strategy (1980). In the humanistic strand are models such as the garbage can model; ${ }^{7}$ the theory of organizational sense making; and studies of organizational culture. These two strands have enjoyed significantly different receptions in eastern and western cultures.

The features of Japanese and western organizations as they relate to organizational knowledge creation are listed in table 2 .

Table 2. J apanese-Style vs. W estern-style Organizational Knowledge Creation

\begin{tabular}{ll}
\hline \multicolumn{1}{c}{ J apanese organizations } & \multicolumn{1}{c}{ Western organizations } \\
\hline Group-based & Individual-based \\
Tacit know ledge-oriented & Explicit knowledge-oriented \\
Strong on socialization and internalization & Strong on externalization and combination \\
Emphasis on experience & Emphasis on analysis \\
Danger of "group think" and over-adaptation to past success & Danger of "paralysis by analysis" \\
Ambiguous organizational intentions & Clear organizational intentions \\
Group autonomy & Individual autonomy \\
Creative chaos through overlapping tasks & Creative chaos through individual differences \\
Frequent fluctuation from top management & Less fluctuation from top management \\
Redundancy of information & Less redundancy of information \\
Variety through cross-functional teams & Variety through individual differences \\
\hline
\end{tabular}

Source: Adapted from Nonaka and Takeuchi 1995, 199.

Japanese and western organizations have evolved their own philosophies and assumptions over time. The thinking of Japanese organizations is very close to that of Chinese traditional philosophy. However, modern Chinese organizations have mixed these ideas with many imports from western philosophy. A truly Chinese style of organization has yet to emerge. The Japanese style reminds us that western organizational styles may not be universal and that both organizational styles have the potential to be universally applicable. Researchers in public administration should realize that neither localization nor internationalization need be dominated by western organizational theory. Research that lacks the critical insight to see this runs the risk of merely simplistically repeating previous patterns.

7. R. L. Daft, 2007. Understanding the theory and design of organization. Mason, OH: Thomson South-Western. 


\section{Epistemological Turn from Western to Eastern}

In the past, public administration studies have been heavily influenced by logical positivism, and have developed as a scientific subject. This bias caused a reaction that led to the rise of a more humanistic approach to public administration. The scientific approach is a western construct, and western researchers believe that it is universal. However, if we accept this argument, then there can be no localization to speak of. The humanistic approach fits Chinese culture much better. It can borrow from the epistemology of Chinese philosophy, in which tacit knowledge is encouraged. This tacit knowledge can be gradually made explicit, and this will allow for internationalization and universal application.

This epistemological turn seeks to free language from the constraints of logic and definitions, and break the grip of logical rules. It is a return to "that which comes before logic." This is the source of eastern mysticism and its tacit knowledge. Our task now-the key to localization in public administration studies-is to find what is universal in this tacit knowledge.

Cassirer indicates (1944, 32-68) that the totality of human life cannot be only expressed as a rational synthesis, expressing oneself within a system of scientific concepts. It also exists in other forms, including language, myth and religion, and art, and is in no way inferior to logic and science. Basically, logical and scientific cognition are no more than a technique for elevating the particular to the level of the universal-a function shared by myths, language, religion, and art. The difference lies in the way in which they achieve this goal (Gan 1987, 84-99).

\section{The Human Science Approach}

Jong S. Jun (1994, 157-59) in his book In Philosophy of Administration, discusses the human science approach to public administration and noted that it takes a phenomenological-hermeneutic approach based on classical political theory; as such, it contrasts with positivist research practices. The human science approach is based on five assertions:

1. Administrative reality is grounded in the meaning of human action as interpreted by the subject.

2. To understand an administrative situation actively, one must study it from the subject's point of view.

3. Understanding is not determined by a theory, but occurs through the researcher's empathy toward the experience of the subject.

4. The primary research method is the interpretation of the meanings of human 
expressions, emotions, and artifacts.

5. Human values are enormously complex, amorphous, irrational, and generally intangible.

The scientific and humanistic approaches to public administration are almost independent parallel fields of study. The scientific strand has basically dominated public administration studies, while the humanistic strand has been neglected. Administrators are complete human beings. They are not, as Simon $(1945,1991)$ claims, absolutely inclined to rationality. In real organizations, the processes of planning and policy execution are a mix of both rational and emotional responses. This is something that is well understood in eastern cultures.

Richard L. Daft, in his famous textbook Understanding the Theory and Design of Organizations, has the following to say:

One problem with the management science approach is that quantitative data are not rich and do not convey tacit knowledge. Informal cues that indicate the existence of problems have to be sensed on a more personal basis by managers. The most sophisticated mathematical analyses are of no value if the important factors can not be quantified and included in the model. Such things as competitor reactions, consumer tastes, and product warmth are qualitative dimensions (Daft 2007, 333).

As mentioned earlier, Polanyi (1958, 1966, 1967) indicated that "we can know more than what we can tell." Tacit knowledge is also known as personal knowledge. It is hard to generalize personal knowledge, because it is not explicit knowledge and can not describe external behavior. Personal knowledge can be categorized as the intentional truth that is experienced by an individual person. As people experience more intuitive truth in their lives, the intuitional capacity of their subconscious may grow.

Intuitive decision making is not arbitrary or irrational because it is based on years of practice and hands-on experience, often stored in the subconscious (Daft 2007, 329). In an age of globalization, it seems that political and economical institutions around the world tend to share similar values such as democracy and market economy, but individual people around the world seem to sense more strongly the phenomenon of cultural difference. We may see a lot of events that have never happened before. Administrators encounter many abnormal phenomena rather than normal ones. Abnormal events may become increasingly common. In such a volatile environment, administrators, especially at higher levels, should have more flexibility to cope with abnormal or crisis events.

Generally speaking, the decision-making process has two stages: problem identifi- 
cation and problem solving. The first stage belongs to the hermeneutic category and involves giving the problem a suitable or clear meaning in order to adopt an effective method to achieve one's goals. In this stage, the agent or stakeholder has to use his or her intuitive capacity or practical experience, which was stored in his or her subconscious a long time ago. The second stage can be categorized as involving technical methods or instruments such as management technology. In the age of globalization, the first stage is more important than the second, because in the era of globalization, the environment is more and more complicate and volatile. When you make a dicision, you have to interpret what is the meaning of the problem. From this viewpoint, differences, especially cultural differences, are more important than similarities.

For many years, public administration studies in both mainland China and Taiwan have been almost totally devoid of reflection on issues of philosophy and cognition. Chinese public administration studies have been a colonial outpost of the western academy, carrying mimicry of its bias to ridiculous extremes. An entire century of public administration studies has been cast entirely in the light of logical rationalism, in an attempt to beat the western tradition at its own game. China's own cultural roots have been abandoned, with the result that Chinese scholars have had little to add to public administration theory.

But the consequences have run much deeper. Recent trends show that the crisis is far from over: alternative college admissions procedures, constructivist teaching of mathematics, and the use of impact factor ratings 8 to assess universities all show the grip of western scientific thinking. Many academic administrators still fervently cling to their belief in quantitative assessment. They insist on the superiority of logic and rationalism, and have yet to understand the power of the humanistic approach. But the latter is precisely where the heart of Chinese culture lies, and without a full appreciation of humanistic research it will be impossible to bring about any real localization of public administration in East Asia, let alone a change in the cognitive paradigm of the field.

\section{CONCLUSION}

The humanistic approach emphasizes human subjectivity, whereas the logical approach strives to avoid the subjective in favor of objective or quantitative research

8. The Institute for Scientific Information maintains citation databases of academic journals, including a continuation of its longtime print-based indexing service the Science Citation Index (SCI), Social Sciences Citation Index (SSCI), and the Arts and Humanities Citation Index (AHCI) (Wikipedia n.d.a). 
paths. These two patterns of thinking correspond to Mou's analysis of truth:

Extensional truth is objective truth that removes itself from the subject and discovers quantities; intentional truth is truth that belongs to the subject, and maintains the importance of her qualities. Mathematics and the natural sciences deal in extensional truths. The truths of morality, religion, social affairs, history and culture are intentional truths. They cannot escape the subject and become purely extensional or quantifiable (Mou 2003, 29:19).

The field of public administration long ago rejected subjectivity and turned to quantification. In doing so, the field has lost its way. The time has come to turn back!

Public administration is the study of people, objects, and the relations between people and objects. It cannot restrict itself to objective, quantitative, scientific approaches. Administration is a part of human life, and as such it not only connects to science, it is also tightly bound up with language, religion, morality, the arts, history, and culture.

The localization of public administration studies means recognizing the primacy of humanistic thinking in Chinese traditional culture. This feature of Chinese culture can complement and supplement the tendency toward logical thinking in western culture. With this epistemological shift, we can finally develop a theory of public administration that is relevant both locally and internationally.

We have used the hermeneutical method to analyze the meaning of administrative action in organizations from different cultural viewpoints. Above all, human action possesses meaning, which is different from animals' external behavior. Behavioral science seeks the general rules of external behavioral performances, similar to the development of academic research in 1950s. But in the 1980s, Argyris, Putnam, and Smith (1985) advocated applying action science to the field of organizational management, and emphasized the fact that action science is not behavioral science. The word "action" in action science is significant, while behavioral science pursues generalizations rather than searching for the meaning of behavior. We need to develop action knowledge, which involves values, significance, and experience factors and elements, because these could be strategies for people to increase their abilities, skills, and confidence in groups, so as to build an organization and to cultivate long-term individual effectiveness.

This paper has discussed the different cultural backgrounds of eastern and western societies and drawn on the thinking of Chinese philosophers such as Confucius, Laozi, and Zhuangzi, as well as the Hungarian-British philosopher Michael Polanyi (1958, 1966, 1967), extraordinary western scientists such as Nobel prize winner Ilya Prigogine $(1984,1997)$ and quantum mechanics inventor Werner Heisenberg $(1975,1999)$, Karl Popper (1968, 1969, 1979), and modern scholars such as Simon (1991), Hsiung (1997, 
1999, 2000), Mou (1960, 2003), Jun (1994, 2006, 2008), and Nonaka and Takeuchi (1995).

In a discussion of knowledge creation, Nonaka and Takeuchi (1995) identified the four categories of sympathized, conceptual, operational, and systemic knowledge and found that western and eastern organizational styles are dissimilar. Confucianism, Buddhism, Taoism, and naturalism have influenced organizational thinking especially in the East, and eastern and western organizations have evolved profoundly different philosophies and assumptions.

The Japanese organizational mindset, similar to that of Chinese tradition, reminds us that western organizational styles are not universal; both eastern and western organizational styles have the potential to be universally applicable. Researchers in public administration should realize that neither localization nor globalization need be dominated by western organizational theory.

Logical positivism sees science as simply a search for truth. But as Popper argues, there is no way to find the truth because of the limits of bounded human rationality, so that science can only be a search for verisimilitude. To oppose logical positivism is because it has been passing out of favor and also because of the assumption that it holds true for all situations. It is not against to the positive method besides positivism as it does not oppose the scientific method besides scientism.

Western traditions often take the approach, as expressed by Simon (1991), the individual is more important than the group and explicit knowledge is more important than tacit knowledge; those are the viewpoints of logical positivism. Chinese epistemological traditions stress the unity of nature and man, mind and body, mind and matter, and self and other. All learning takes place inside individual human beings, so all organizational learning is individual learning. And an organization's competitiveness depends on its tacit knowledge, not explicit knowledge.

Due to the global economic crisis that began in 2008, which was astonishing to our imaginations, we need to develop action knowledge to support theories of how financial crises developed as well as how they can be avoided, so as to reform the institutionalized paradigm of public administration and governance, and to cooperate to deal with the economic crisis.

\section{REFERENCES}

Agyris, C., R. Putnam, and D. Smith. 1985. Action science. San Francisco: Jossey-Bass.

Barnard, C. I. 1938. The functions of the executive. Cambridge, MA: Harvard University Press. 
Capra, F. 1982. The turning point: Science, society and the rising culture. New York: Simon and Schuster.

1985. The Tao of physics: An exploration of the parallels between modern physics and eastern mysticism, 2nd ed. Boston: Shamlihala.

Cassire, E. 1944. An essay on man: An introduction to a philosophy of human culture. New Haven: Yale University press.

Cook, S. D. N., and J. S. Brown. 1999. Bridging epistemologies: The generative dance between organizational knowledge and organizational knowing. Organization Science 10(4): 381-400.

Daft, R. L. 2007. Understanding the theory and design of organization. Mason, OH: Thomson South-Western.

Emerson, T. and Sheridan B. 2009. Dominique Strauss-Kahn: The constant crisis, Newsweek, Sep 26, 2009, From the magazine issue dated Oct 5, 2009 http:// www.newsweek.com/id/216214.

Gan, Y. 1987. From rational criticism to cultural criticism. Contemporary Magazine 20: 84-99.

Harmon, M.1981. Action threory for public admnistration. New York, NY: Longman Inc.

Heisenberg, W. 1975. Development of concepts in the history of quantum theory. American Journal of Physics 43(5): 389-394.

2007. Physics and philosophy: The revolution in modern science. New York: Harper and Row.

Hsiung, S. 1997. 原儒 [Origins of Confucianism], 2nd ed. Taipei: Aloha.

1999. 讀經示要 [Essentials for reading the classics], 2nd ed. Taipei: Aloha.

2000. 新唯諳棓侖[A new theory of consciousness-only], 2nd ed. Taipei: Aloha.

Jun, J. S. 1994. Philosophy of administration. Seoul: Daeyoung Moonhwa International. . 2006. The social construction of public administration: Interpretive and critical perspectives. Albany: The State University of New York Press.

. 2008. The social construction of public administration: Interpretive and critical perspectives. Beijing: Beijing University.

Kindleberger, C. P., and R. Aliber. 2005. Manias, panics, and crashes: A history of financial crises, 5th ed. Hoboken, NJ: Wiley.

Kuroda, H. 2009, Asia's recovery from the global financial crisis-What it takes and what could $A D B$ do? Lactured on 22 June 2009, at the Institute of Southeast Asian Studies. http://www.adb.org/Documents/Speeches/2009/ms2009049.asp.

Laeven, L., and F. Valencia. 2008. Systemic banking crises: A new database. IMF Working Paper 08/224. Washington, DC: International Monetary Fund.

Lee, S. 2004. 王陽明傳習錄 [An Essay on collective learning of Wang young ming]. 
Taipei: San Min.

Lincoln,Y. S., and E. G. Guba. 1985. Naturalistic inquiry. Los Angeles: Sage Publications.

MacNamara, R., and B. VanDeMark 1995. In retrospect: The tragedy and lessons of Vietnam. New York, NY: Times Books.

Mou, Z. 1960. Preface of age of the state and historical cultures. 人生亲隹志 [Humanity Magazine] 21(4).

. 2003. 牟宗三全集 [Complete works]. Lectures on Chinese Philosophy 29:

19. Taipei: Linking Book Company.

Nonaka, I., and H. Takeuchi. 1995. The knowledge-creating company. Oxford: Oxford University Press.

Polanyi, M. 1958. Personal knowledge. Chicago: University of Chicago Press. . 1966. The tacit dimension. New York: Doubleday. 1967. The tacit dimension. New York: Anchor Books.

Popper, K. R. 1968. The logic of scientific discovery. New York: Basic Books. . 1969. Conjecture and refutations: The growth of scientific knowledge. London: Routledge \& Kegan Paul.

1979. Objective knowledge: An evolutionary approach. Oxford: Oxford University Press.

Porter, M. 1980. Competitive strategy: Techniques for analyzing industries and competitors. New York: Free Press.

Prigogine, I., and I. Stengers. 1984. Order out of chaos: Man's new dialogue with nature. New York: Bantam Books.

Simon, H. A. 1945. Administrative behavior. NewYork: MacMillan. . 1991. Bounded rationality and organizational learning. Organization Science, 2(1): 125-134.

Schwartz, P. and J. Ogilvy. 1979. The emergent paradigm: Changing patterns of thorght and belief. Analytic Report 7, Values and Lifestyles Program. Menlo Park, CA: SRI International.

Tang, J. 1991. 唐君毅全集[Complete works of Tang Junyi]. Taipei: Student Press.

Taylor, F. W. 1911. Principles of scientific management. New York and London: Harper \& Brothers.

Wikipedia. n.d.a. Institute for Scientific Information. http://en.wikipedia.org/wiki/Institute_for_Scientific_Information.

Wu, C. 2005. Public administration: Scope and methods. Taipei: Wu-Nan. . 2006. Public administration, 3rd ed. Taipei: San Min. 